\title{
STRENGTH AND DURABILITY PROPERTIES OF WASTE STEEL SLAG MIXED CONCRETE
}

\author{
Abhijit Warudkar ${ }^{1,2^{*}}-$ S. Elavenil ${ }^{3}$ \\ ${ }^{1}$ School of Civil Engineering, VIT University, Chennai. India \\ ${ }^{2}$ Deptartment of Civil Engineering, ICOER, Pune, India \\ ${ }^{3}$ School of Civil Engineering, VIT University, Chennai, India

\section{ARTICLE INFO}

\section{Article history:} \\ Received: 16.4.2020. \\ Received in revised form: 8.10.2020. \\ Accepted: 12.10.2020. \\ Keywords: \\ Compressive strength \\ Steel slag mixed concrete \\ Durability-related properties \\ DOI: https://doi.org/10.30765/er.1628

\begin{abstract}
:
The exploration of natural aggregates for construction leads to the degradation of the environment; thus, the development of environment-friendly construction materials, such as steel slag, is being promoted. Disposal of steel slag without affecting ecology is the central issue of concern, as steel industries produce a million tonnes of steel slags as a by-product every year. To address this issue, we studied the potential of a waste steel slag to use as a replacement of coarse aggregate in the cement concrete. We observed that the mixing of waste steel slag with concrete improves the mechanical and durability properties of the concrete. The abrasion properties of steel slag concrete are comparable with a coarse aggregate concrete. The study concludes that the use of steel slag in concrete improves the physical properties of the cement concrete, and thus, steel slag concrete can be used for building floorings, pavements, or concrete surfaces, which expose to the external forces and severe weather conditions.
\end{abstract}

\section{Introduction}

Cement concrete is a primary construction material used in almost all types of construction projects such as pavements, buildings, hydraulic structures. The large quantity of concrete is being produced in the world, which needs large quantities of concrete ingredients (i.e. cement, fine aggregate, coarse aggregate, and water). The properties of concrete ingredients govern the quality of concrete [1], [2]. Aggregates occupy about $70 \%$ volume of the concrete. Limited natural resources are available for aggregates in India and other parts of the world. Governments are imposing restrictions on explorations of natural aggregates, due to its destructive effect on the environment. Therefore, it is high time for researchers and engineers to find a suitable replacement for aggregates.

Use of the artificial industrial slag instead of natural aggregates is becoming popular for producing sustainable concrete [1] [3]. Steel slag improves the strength and the durability of the concrete; if its sulphate content and water absorption are limited to $0.5 \%$ and $10 \%$, respectively [4]. Calcium oxide $(\mathrm{CaO})$ present in the steel slag aggregate can partially or entirely act as a binder in the concrete. Steel slag improves the bearing capacity of the concrete, if it is used as a cement bound base coarse [5]. Workability and mechanical strength of the concrete significantly improve by replacing coarse aggregate with a steel slag up to $75 \%$ [6], [7]. Steel slag mixed in the concrete (up to $60 \%$ ) instead of coarse aggregates improved the compressive strength of M20, M30, M40 and M50 grades concrete by $4 \%$ to $7 \%$ [8]. Steel slag aggregates are lightweight and show lower water absorption compared to brick aggregates.

Concrete mixed with steel slag aggregate shows improved workability, modulus of elasticity, tensile strength, and ultrasonic pulse velocity (UPV) properties as compared to the concrete which has brick aggregates. The modulus of elasticity of different concrete mixes varies with the type of steel slag aggregates

\footnotetext{
${ }^{*}$ Corresponding author

E-mail address: abhijit.warudkar@gmail.com, warudkar.abhijitarao2014@vit.ac.in
} 
[9]. The workability of the controlled concrete (prepared using coarse aggregates) and the steel slag mixed concrete (prepared by replacing $45 \%$ of coarse aggregates by steel slag aggregate) is similar. The porous surface of steel slag aggregates along with sulfate attacks slightly changes the compressive strength of concrete. Sorptivity and water absorption properties of the concrete does not changes when the concrete is mixed with steel slag aggregates [3][10]. The concrete prepared using steel slag aggregates (up to $20 \%$ ) do not negatively affect the short term properties of hardened concrete [11].

The workability property of steel slag mixed concrete varies with the volume of aggregate replacement. The slump of concrete decrease with an increase in the amount of steel slag aggregates. The water absorption capacity of steel slag aggregate is slightly higher than the natural stone aggregates. The increase of $0 \%$ in replacement, leads to a $10 \%$ decrease in a slump. Remarkable improvement in the compressive strength (about $23 \%$ ), flexural strength (about $40 \%$ ), and tensile strength of 7 days and 28 days concrete has been reported in the literature. Partial replacement of coarse aggregate with a steel slag shows a better resistance to $\mathrm{HCl}$ and $\mathrm{H}_{2} \mathrm{SO}_{4}$. All replacement combination (up to $50 \%$ ) shows low chlorine penetrability[12]. Mechanically, steel slag mixed concrete showed improvement in the compressive strength, flexural strength and tensile strength with an increase in the percentage replacement[13].

An experimental study has pointed out that the desired compressive strength of high strength concrete can be achieved if the replacement of the coarse aggregate by steel slag aggregate is less than to $50 \%$. Replacement of coarse aggregate by steel slag aggregate of up to $36 \%$ could maintain the desired compressive strength of the concrete; however, flexural and tensile strength did not affect due to the replacement [14]. The consistency of the steel slag mixed concrete decrease by $28 \%$ to $34 \%$ immediately after mixing and after 30 minutes of mixing. The density of the fresh concrete (steel slag mixed) varies from $2728 \mathrm{~kg} / \mathrm{m}^{3}$ to $2863 \mathrm{~kg} / \mathrm{m}^{3}$ [15]. The fluidity of the paste improves when steel slag powder is used as a mineral admixture in the concrete. Use of steel slag as aggregates have shown higher compressive strength of an Ultra-High-Performance Concrete (UHPC) under high temperature curing conditions at early stages, and steel slag aggregates were reacted and connected tightly with the hardened paste[16].

Generally, the concrete surfaces are, most of the time, exposed to the adverse environmental conditions, loading, abrasive actions, especially in case of concrete pavements. However, limited information is available in the literature on durability properties, and the abrasion resistance of the steel slag mixed concrete prepared for the flooring or pavement purpose. Exposure of the concrete surfaces to the several abrasive actions may lead to the failure of concrete pavement [17], [18]. In this work, we investigate the structural, surface and electrochemical behaviour of the steel slag concrete as a replacement option to the coarse aggregate. The replacement of coarse aggregate with a steel slag may help in optimising the cost and to defeating environmental concerns.

\section{Materials and mix design}

General-purpose cement manufactured by Birla, Ordinary Portland Cement of 53 grades, confirming to IS 12269: 1989 with specific gravity 3.15 and normal consistency of $32 \%$ was used in this work [19]. The river sand used in present work confirms to Zone II as per IS 838: 1970 [20]. The coarse aggregate of $20 \mathrm{~mm}$ nominal maximum size derived from stone crushing was used to prepare concrete. Steel slag with the chemical composition of $\mathrm{CaO}(50-55 \%), \mathrm{MgO}(8-11 \%)$ and $\mathrm{SiO}_{2}(16-21 \%)$ was procured from ISMT, Steel Manufacturing Unit, Pune (India). Table 1 shows the physical properties of the fine and coarse aggregates.

The specific gravity and water absorption were determined using the mesh bucket method. Aggregates with a clean surface were kept into the bucket and bucket was immersed 25 times in the water. The weight (A) is the measured weight of bucket with aggregates in water (note that the water level was $25 \mathrm{~mm}$ above aggregates). The weight (B) is the weight of the dried aggregate whose surface was dried with a cloth. Weight (C) is the weight of the over dried aggregates which were kept in the oven for 24 hours at $100^{\circ} \mathrm{C}$ to $110^{\circ} \mathrm{C}$. The specific gravity and water absorption were calculated using equation $1 \& 2$ [21].

$$
\text { Specific Gravity }=\frac{C}{B-A}
$$


Water Absorption $=\frac{100(B-C)}{C}$

The particle size distribution of aggregates was determined using sieve analysis. Aggregates were ovendried at $100{ }^{\circ} \mathrm{C}$ to $110{ }^{\circ} \mathrm{C}$ for sieve analysis. Sieves used to analyse coarse aggregates are $20 \mathrm{~mm}, 12.5 \mathrm{~mm}$, $10 \mathrm{~mm}, 6.3 \mathrm{~mm}, 4.75 \mathrm{~mm}$ and $3.36 \mathrm{~mm}$ while for fine aggregates are $4.75 \mathrm{~mm}, 2.36 \mathrm{~mm}, 1.18 \mathrm{~mm}, 600 \mu \mathrm{m}$, $300 \mu \mathrm{m}$ and $150 \mu \mathrm{m}$. Fineness modulus of aggregates was estimated by cumulative percentage retention of the aggregate on each sieve [22]. The zone of fine aggregates was decided based on Indian standard 383 [20], which was used in the concrete mix design.

The concrete mix was designed for M30 grade as per IS 10262:(2000) [23]. A good degree of supervision, concrete in mild exposure, and $50 \mathrm{~mm}$ slump value of workability in a direct placing condition were considered during mix design. The proportions of cement: fine aggregate: coarse aggregate adopted for all mixes was 1: 1.75: 2.86. Coarse aggregate was partially and fully replaced by steel slag in different proportions $(0 \%, 25 \%, 75 \%$ and $100 \%)$.

The water-cement ratio of the control mix and the steel slag mixed concrete was 0.48 . The same cement content was used for all samples. The coarse aggregate was replaced by steel slag, maintaining the same quantity of fine aggregates. The effect of the addition of steel slag on the total volume and weight were ignored. The nomenclatures of different samples used in this study and the corresponding mix proportions are as given in Table 2.

\section{Test specimen and procedure}

Tests for compressive strength, flexural strength and split tensile strength were conducted to assess the performance of steel slag mixed concrete. Test specimens were cast in line with the requirement of Indian Standards (i.e. $150 \mathrm{~mm}$ cube, $700 \mathrm{~mm} \times 150 \mathrm{~mm} \times 150 \mathrm{~mm}$ beam and $150 \mathrm{~mm}$ dia, $300 \mathrm{~mm}$ height cylinder respectively) [4], [24].

The abrasion test (surface wear) was conducted as per IS: 1237: 1980 [25] on 28 days cured concrete specimen of $40 \mathrm{~mm}$ depth. $50 \mathrm{~cm}^{2}$ surface area of the concrete specimen was exposed to abrasion to evaluate the behaviour of steel slag mixed concrete surface under abrasion conditions. Rapid chloride penetration test (RCPT) was performed to determine the penetration of chloride ions through 28 days cured concrete specimen; test performed according to ASTM C1202 [26]. Ultrasonic pulse velocity test was conducted to examine the concrete homogeneity after mixing of steel slag, as per IS 13311 (part 1):1992 [27]. We note that all experiments in the present work were conducted in triplicate. The results of the experiments were evaluated using mean value and standard deviation of the three experiments. The error bar in the graph shows a $95 \%$ confidence interval. Note that the concrete specimens were cured for 28 days. Tests were carried out on the compressive testing machine and universal testing machine of 100 tonnes and 200 tonnes capacity respectively, as shown in Figure 1.

The load was applied axially on specimen without shocks until crushing of the specimen. The specimen resisted the failure in bending when applied a single point load during the flexural test. Split tensile strength was conducted as per the IS 5816-1999 (reaffirmed 2004) [28] without shock, and the load was increased continuously from $1.2 \mathrm{~N} / \mathrm{mm} 2 / \mathrm{min}$ to $2.4 \mathrm{~N} / \mathrm{mm} 2 / \mathrm{min}$ during experiment.

Table 1. Properties of aggregates.

\begin{tabular}{cccccc}
\hline $\begin{array}{c}\text { Sr. } \\
\text { No. }\end{array}$ & Property & Fine aggregate & Coarse aggregate & Steel slag & Remark \\
\hline 1 & Specific gravity [21] & 2.66 & 2.67 & 2.61 & \\
2 & Water absorption [21] & $1.25 \%$ & $1.20 \%$ & $1.14 \%$ & \\
3 & Silt content [29] & $4.03 \%$ & - & - & \\
4 & Sieve analysis [22] & & FM $=4.39$ & FM= 4.98 & \\
5 & Impact value [30] & - & $7.89 \%$ & $16.93 \%$ & Should not exceed 30\% \\
6 & Abrasion: Los Angeles [30] & & $23.43 \%$ & $25.86 \%$ & Maximum permissible 30\% \\
\hline
\end{tabular}


Table 2. Mix proportions of M30 grade fresh concrete $\left(\mathrm{kg} / \mathrm{m}^{3}\right)$.

\begin{tabular}{ccccccc}
\hline $\begin{array}{c}\text { Sample } \\
\text { Name }\end{array}$ & $\begin{array}{c}\text { Cement } \\
(\mathrm{kg})\end{array}$ & $\begin{array}{c}\text { Water } \\
(\mathrm{kg})\end{array}$ & $\begin{array}{c}\text { Fine aggregate } \\
(\mathrm{kg})\end{array}$ & $\begin{array}{c}\text { Coarse aggregate } \\
(\mathrm{kg})\end{array}$ & $\begin{array}{c}\text { Steel slag } \\
(\mathrm{kg})\end{array}$ & Remark \\
\hline S1 & 387.5 & 186 & 680 & 1110 & - & $\begin{array}{c}\text { Control mixture } \\
\text { S2 }\end{array}$ \\
387.5 & 186 & 680 & 832.5 & 277.5 & $\begin{array}{c}25 \% \text { replacement of coarse } \\
\text { aggregate by steel slag }\end{array}$ \\
S3 & 387.5 & 186 & 680 & 555 & 555 & $\begin{array}{c}50 \% \text { replacement of coarse } \\
\text { aggregate by steel slag }\end{array}$ \\
S4 & 387.5 & 186 & 680 & 277.5 & 832.5 & $\begin{array}{c}75 \% \text { replacement of coarse } \\
\text { aggregate by steel slag } \\
100 \% \text { replacement of coarse } \\
\text { aggregate by steel slag }\end{array}$ \\
\hline
\end{tabular}

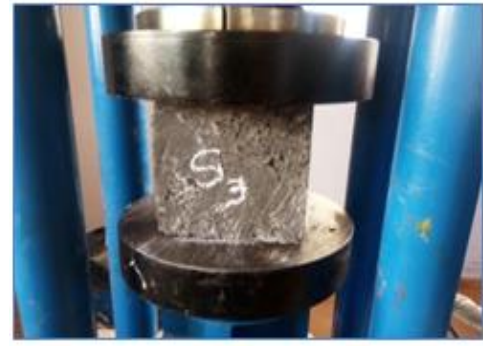

a)

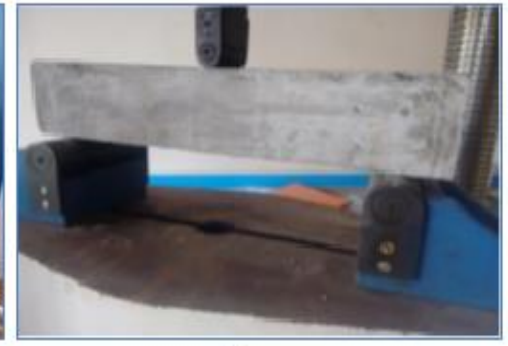

b)

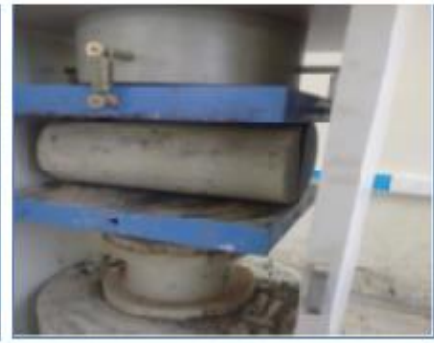

c)

Figure 1. a) compressive test b) flexural test c) split tensile test of 28 days cured concrete specimen.

The result in terms of average abrasion depth and an average percentage of abrasion loss was measured during the abrasion resistance test. The abrasive powder had a hardness of 9 in Morh's scale, the specific gravity of 3.9 to 4.1 , and aluminium oxide content was less than $95 \%$ by weight.

The specimen was fixed in the holding device with a test surface oriented toward the ground face of the rotating disc. The speed of the rotating disc was $30 \mathrm{rev} / \mathrm{min}$, and the specimen was loaded with $300 \mathrm{~N}$ at the centre.

The specimen rotated in $90^{\circ}$ after 22 revolutions, and $20 \mathrm{~g}$ of abrasive powder was spread on grinding path at each rotation. The test was completed after 220 revolutions [25]. As per the IS code, for heavy-duty floors, average maximum wear shall not exceed $2 \mathrm{~mm}$, and any individual specimen shall not exceed 2.5 $\mathrm{mm}$. In general-purpose tiles, it is $3.5 \mathrm{~mm}$ and $4 \mathrm{~mm}$ respectively. Abrasion loss was measured in terms of loss in depth and loss in weight, using a Vernier Caliper with $0.02 \mathrm{~mm}$ least count (see Figure 2) and weighing machine of $0.001 \mathrm{~g}$ least count respectively. 


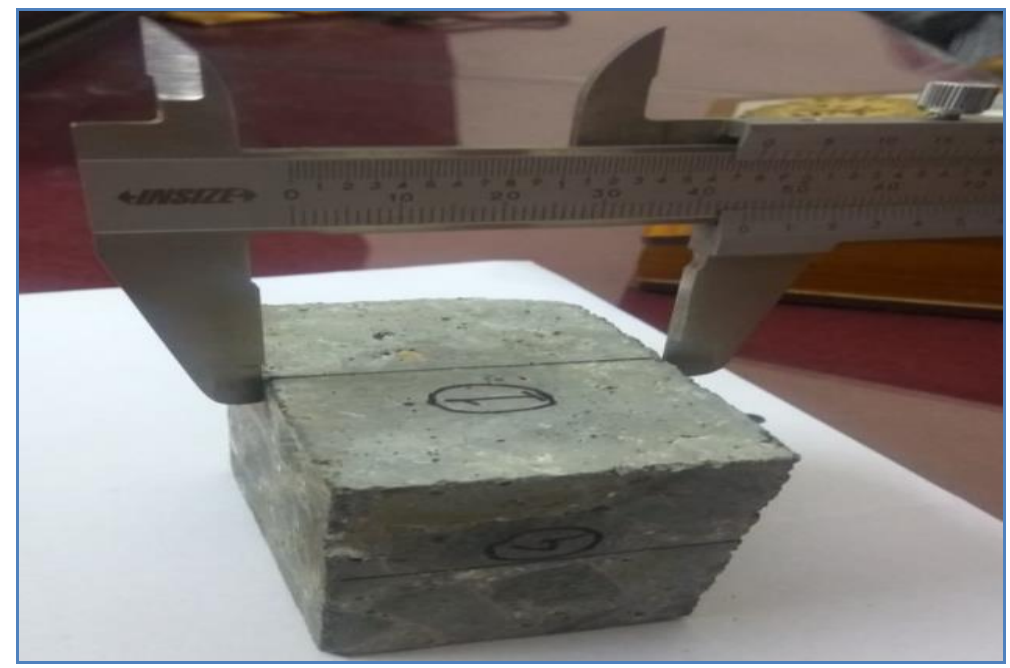

Figure 2. depth measurement of concrete specimen.

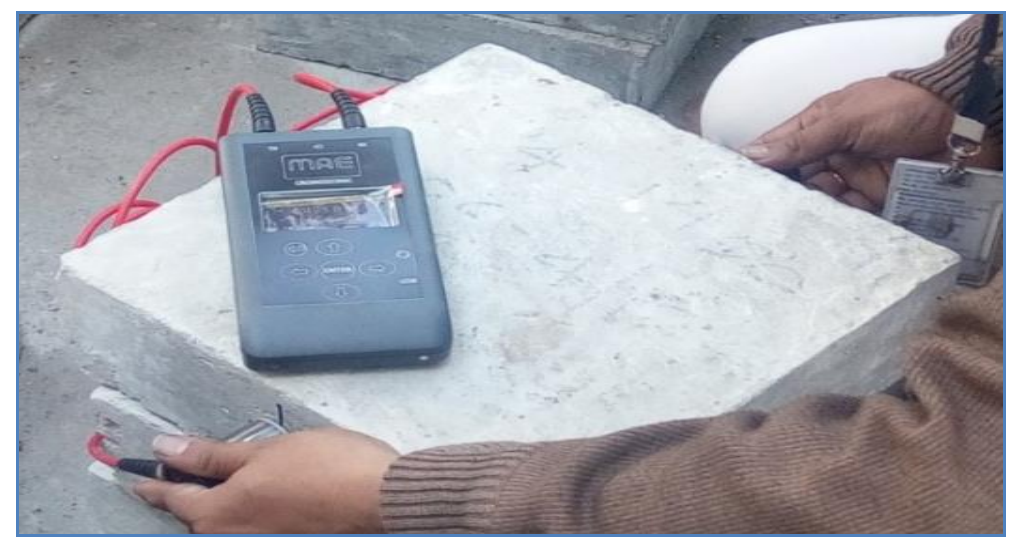

Figure 3. Measurement of ultrasonic pulse velocity in a concrete specimen.

The ultrasonic pulse generated by an electro-acoustic transducer undergoes multiple reflections at the boundaries of different material phases. The pulse generated is independent of the geometry of material through which it transmit, and it depends only on the elastic properties of the concrete. Higher pulse velocities indicate that the quality of concrete in terms of density, homogeneity and uniformity is good. Tests were conducted on $300 \mathrm{~mm} \times 300 \mathrm{~mm} \times 100 \mathrm{~mm}$ slab specimen, as shown in figure 3 , and $150 \mathrm{kHz}$ natural frequency was transmitted through the $300 \mathrm{~mm}$ path length. Velocity observed was noted for further analysis of the quality of concrete [27].

The penetrability of chloride ions indicates the availability of the pours and its interconnections in the concrete. This penetrability of chloride ions affects the quality of concrete. Ingress of chloride ions into steel slag mixed concrete was evaluated on a 28 days cured concrete sample by rapid chloride penetration test (RCPT) and as per ASTM C1202. Concrete specimens for the test were cast in $100 \mathrm{~mm}$ diameter and $50 \mathrm{~mm}$ height, kept mould in desiccators for 18 hours and 3 hours in unionized water. Specimens worked as a media for the flow of ions when a potential difference of $60 \mathrm{~V} \mathrm{DC}$ was maintained using $30 \% \mathrm{NaCl}$ and $0.3 \mathrm{M}$ $\mathrm{NaOH}$ solution. Total charge flow was calculated in Coulombs to find the resistance of the specimen to chlorine ion penetration [26].

\section{Result and discussion}

This study evaluates the properties of M30 grade of concrete when mixed with different percentage of steel slag. Figure 4 depicts that replacing coarse aggregate with a steel slag increases the compressive, flexural and tensile strengths of the concrete, except the compressive strength of the S2 sample (See Figure 4a). The compressive strength of S2 sample, which had $25 \%$ steel slag, is lower compared to the other 
samples. This may be due to improper workmanship or uneven compaction of the sample. We note that the same experimental procedure was adopted during all experiments.

The compressive strength of the concrete varies from $37.48 \mathrm{~N} / \mathrm{mm}^{2}$ to $45.32 \mathrm{~N} / \mathrm{mm}^{2}$. The flexural and tensile strengths of the concrete increase with an increase in the steel slag proportion (see Figure $3 \mathrm{~b}$ ). We observed the highest value of compressive strength $\left(45.32 \mathrm{~N} / \mathrm{mm}^{2}\right)$, flexure strength $\left(5.16 \mathrm{~N} / \mathrm{mm}^{2}\right)$, and split tensile strength $\left(3.96 \mathrm{~N} / \mathrm{mm}^{2}\right)$ of concrete mix which had $75 \%$ of steel slag. Many physical actions cause abrasion of the concrete surface. Figure 5 shows the percentage abrasion loss of three tested concrete specimens over a range of proportion of steel slag $(0-100 \%)$ in a concrete mix. We note that concrete specimens were tested for abrasion after 28 days of curing.

Figure 5 clearly shows that the concrete mix without steel slag (i.e. $0 \%$ steel slag, controlled specimen, S1) exhibits better abrasion resistance as compared to the steel slag mixed concrete. The average value of abrasion loss percentage gradually varies from $1.62 \%$ to $2.27 \%$, with an increase in the proportion of steel slag in concrete at the age of 28 days. These results demonstrate that the natural aggregate has less abrasion loss compared to the steel slag concrete, and an increase in steel slag content in the concrete increases the loss of concrete due to abrasion.

The impact value and abrasion properties of the steel slag (see table 1) could be the reason for higher abrasion loss of steel slag concrete. The impact value and the abrasion of steel slag is $9 \%$ and $2.43 \%$ more compared to the coarse aggregate, which increases the abrasion resistance of the coarse aggregates. We note that the abrasion loss percentage of nature aggregate mix concrete and steel slag mix concrete after 28 days of curing ranged from $0.77 \%$ to $3.90 \%$ (see Figure 5) over a range of tested specimens. We applied a linear regression to establish the relationship between abrasion loss (AL) and the proportion of steel slag (PSL) in the concrete mix. We found the relationship as given in Eq. 3.

$$
A L=\alpha \times P S L+\beta
$$

Here, AL is the abrasion loss (\%), PSL is the proportion of the steel slag in the concrete mix, $\alpha$ is a coefficient which represents the rate of change of abrasion loss with respect to the steel slag proportion, and $\beta$ is abrasion loss coefficient (\%) which indicates the abrasion loss without the addition of steel slag in the concrete. Note that coefficients values are applicable for a given set of experimental condition only. In the present work, we fitted the average value of abrasion loss with the proportion of steel slag, as shown in Figure 5. We obtained $\alpha=0.66$ and $\beta=1.588$. These results indicate that the abrasion loss increases linearly with an increase in the proportion of steel slag in the concrete.

In Figure 4, the symbol shows the average value of three experiments, and the error bar shows a $95 \%$ confidence interval. Note that the proportion of steel slag in sample S1, S2, S3, S4, S5 are 0, 0.25, 0.5, 0.75, 1 respectively.

In Figure 5, the symbol shows the average value of three experiments. The continuous line shows the fitting of an average value of abrasion loss with a steel slag content in the concrete mix. (Error bar shows a $95 \%$ confidence interval). Note that the proportion of steel slag in sample S1, S2, S3, S4 and S5 are 0, 0.25, $0.5,0.75,1$ respectively. 

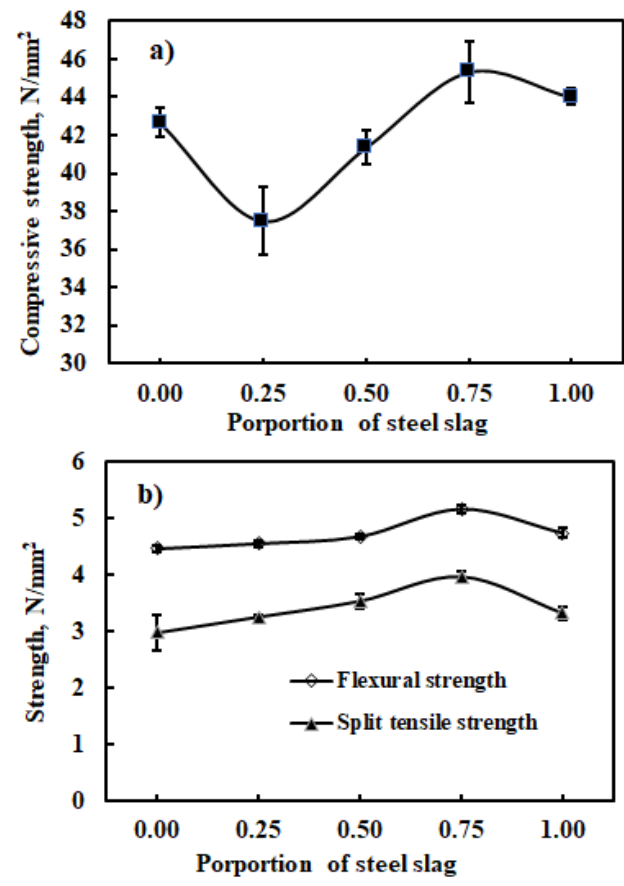

Figure 4. Comparison of the a) compressive strength b) flexural strength and split tensile strength of steel slag mixed concrete at the various proportion of steel slag in concrete.

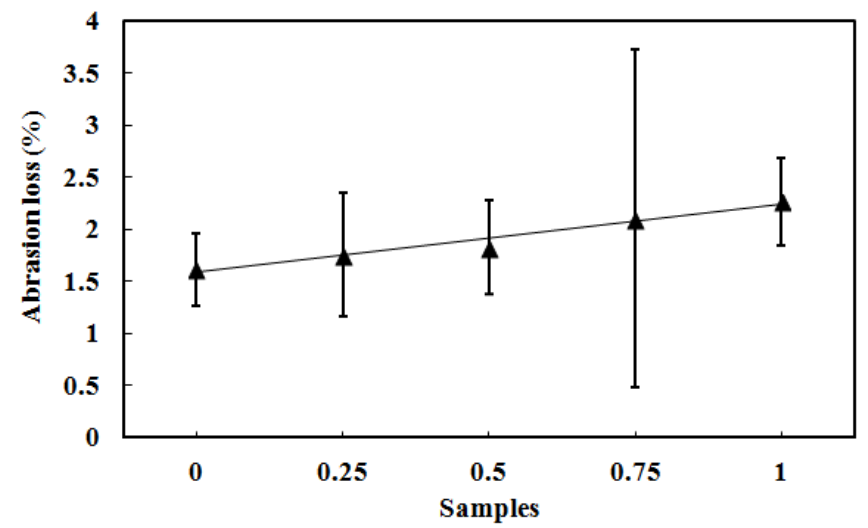

Figure 5. Comparison of the abrasion loss (\%) with the proportion of steel slag present in a concrete mix.

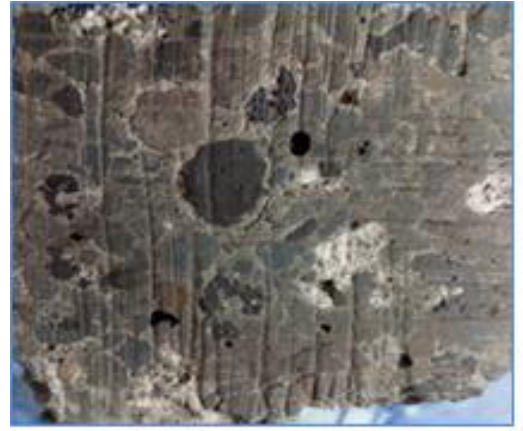

a)

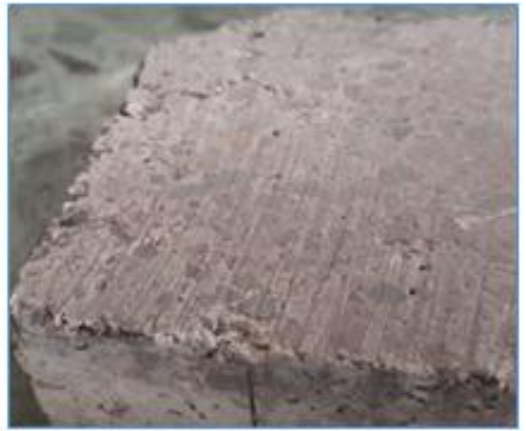

b)

Figure 6. Surface of the concrete after abrasion test a) steel slag concrete b) controlled concrete (coarse aggregate concrete). 
Table 3. Average abrasion depth, concrete quality-based grading and chloride ion permeability of steel slag mixed concrete.

\begin{tabular}{lccccc}
\hline \multirow{2}{*}{ Sample } & \multicolumn{2}{c}{ Abrasion test } & \multicolumn{2}{c}{ Ultrasonic pulse velocity test } & \multicolumn{2}{c}{ Chloride-ion penetration test } \\
\cline { 2 - 6 } & $\begin{array}{c}\text { Abrasion depth } \\
(\mathrm{mm})\end{array}$ & $\begin{array}{c}\text { Pulse velocity } \\
(\mathrm{km} / \mathrm{s})\end{array}$ & $\begin{array}{c}\text { Concrete quality } \\
\text { grading }\end{array}$ & $\begin{array}{c}\text { Charged flow } \\
\text { (Coulombs) }\end{array}$ & $\begin{array}{c}\text { Chloride-ions } \\
\text { Permeability }\end{array}$ \\
\hline S1 (0 \% SS) & $0.98 \pm 0.14$ & $3.95 \pm 0.67$ & Good & $1719.2 \pm 5.45$ & Low \\
S2 (25\% SS) & $0.99 \pm 0.23$ & $2.38 \pm 0.21$ & Doubtful & $1369.2 \pm 6.25$ & Low \\
S3 (50\% SS) & $0.91 \pm 0.31$ & $4.06 \pm 0.06$ & Good & $2781.2 \pm 9.29$ & Moderate \\
S4 (75\% SS) & $1.11 \pm 0.13$ & $4.19 \pm 0.09$ & Good & $3920.2 \pm 2.73$ & Moderate \\
S5 (100\% SS) & $1.32 \pm 0.24$ & $3.52 \pm 0.38$ & Good & $3270.4 \pm 8.89$ & Moderate \\
\hline
\end{tabular}

Table 3 shows that the measured value of abrasion depth of wear varies from $0.97 \mathrm{~mm}$ to $1.32 \mathrm{~mm}$. For all mixes, the depth of wear is less than $2 \mathrm{~mm}$, which indicate that the concrete mix can be utilised for work such as heavy-duty floor tiles and light-duty floor tiles as per IS: 1237: 1980 [25]. An increase in the steel slag proportion in the concrete mix does not show significant variation in the abrasion depth, except for 100 $\%$ steel slag mix concrete. Thomas et al. observed an abrasion depth of $1.42 \mathrm{~mm}$ of a controlled concrete mix, which is similar to the observation made in the present work. Thomas added rubber particles in the concrete to increase concrete abrasion resistance [31].

Figure 6 shows that the abrasion of steel slag mixed concrete is almost similar to the natural aggregate mixed concrete. The steel slag mixed in the concrete act similar to the stone aggregate, further, surface properties of the concrete do not significantly change due to the addition of steel slag in the concrete. The abrasion properties of steel slag aggregates and coarse aggregate (see table 1) affects the abrasion of properties the concrete. Abrasion property of aggregates affects the abrasion properties of concrete when the surface of the concrete is loss due to abrasion and abrasion of the coarse aggregates initiated. This means that the hardened concrete surface is required for minimising abrasion loss. Figure 6 depicts that the abrasion depth is limited to the laitance; once the abrasive forces come in contact with the aggregates of concrete, the abrasion resistance is more. This means that the loss due to abrasion is mostly restricted to the top surface of the concrete. These results imply that the abrasion of controlled concrete is almost similar to the steel slag mixed concrete.

We utilised ultrasonic pulse velocity method to assess the quality of the concrete. The velocity of the pulse in the steel slag mixed concrete ranged from $2.380 \mathrm{~km} / \mathrm{sec}$ to $4.185 \mathrm{~km} / \mathrm{sec}$, which indicate the excellent quality of the concrete. All concrete mix (controlled and steel slag mixed) tested in the present work was good in density, uniformity, and homogeneity. The highest pulse velocity (i.e. $4.185 \mathrm{~km} / \mathrm{sec}$ ) was observed in a $75 \%$ steel slags mixed concrete (see Table 3 ).

We evaluated the suitability of steel slag in a concrete pavement by measuring the resistance of the steel mixed concrete to chloride-ions. The results, as given in Table 3, indicate that the steel slag mixed concrete possess low to moderate chloride ion penetrability. The $25 \%$ steel slag concrete mix had the lowest chloride ion permeability (i.e. 1369.2 coulombs). Although $75 \%$ steel slag concrete mix showed highest chloride ion penetrability (i.e. 3920.2 coulombs), it was within a moderate range. These results indicate that the steel slag mixed concrete can be used for the structures where the moderate type of chloride ion penetration is allowed and specified in the quality manual.

\section{Conclusions}

This study culminates that the steel slag mixed concrete can be utilised as a general-purpose concrete in line with a requirement of IS 10262. The present work showed an increase in the compressive, flexural and tensile strength properties of steel slag mixed concrete that were prepared by replacing $75 \%$ of coarse aggregate with a steel slag aggregate. The addition of steel slag (over a range of steel slag proportion) in concrete does not significantly affect the abrasion resistance.

The concrete prepared using steel slag was good in density, uniformity and homogeneity, and thus it can be utilised for heavy-duty and light-duty concrete flooring surfaces. Moreover, steel slag mixed concrete can be used for the projects wherein moderate chloride ion penetrability is acceptable. The cement concrete pavement design requires concrete which a) has good mechanical strength, b) good quality grading, c) moderate chloride ion penetration and, d) is resistance to the abrasive forces. The steel slag mixed concrete 
fulfil all above requirements, which suggest that steel slag mixed concrete can be utilised for building cement-concrete pavements.

\section{References}

[1] Shetty. M. S.: Concrete Technology Theory and Practice Types of Cement, S. Chand \& Company LTD, New Delhi, 2005.

[2] Warudkar, A., Elavenil, S., Arunkumar, A.: Assessment of abrasion resistance of concrete pavement for durability, International Journal Civil Engineering and Technology, 9 (2018), 6, 1176-1181. [Online].

Available:https://www.scopus.com/inward/record.uri?eid=2-s2.085049592297\& partnerID=40\&md5=c94d2d3045019182ccab201a1e1917d9.

[3] Warudkar, A., Elavenil, S.: Technical Feasibility of Sustainable Steel Slag Mixed Concrete, International Journal Innovation Technology and Exploring Engineering, 8 (2019), 6, 883-887.

[4] Bureau of Indian Standards: Plain and Reinforced Concrete- Code of practice, IS 456 (2000), India.

[5] Barišić, I., Dimter, S., Netinger, I.: Possibilities of Application of Slag in Road Construction, Technical Gazette 17(2010), 4, 523-528.

[6] Warudkar, A., Nigade, Y.: Technical Assessment on Performance of Partial Replacement of Coarse Aggregate by Steel Slag in Concrete, International Journal of Engineering Trends and Technology, 30(2016), 1, 37-41.

[7] Vasanthi, P.: Flexural Behaviour of Reinforced Concrete Slabs Using Steel Slag As Coarse Aggregate Replacement, International Journal of Research in Engineering and Technology, 03 (2015), 09, 141146.

[8] Ravikumar, H., Dattatreya, J., Dr. Shivananda, K.: Experimental Investigation on Replacement of Steel Slag as Coarse Aggregate in Concrete, Journal of Civil Engineering and Environmental Technology, 2 (2015), 11, 58-63. [Online]. Available: http://www.krishisanskriti.org/jceet.html.

[9] Mohammed, T., Rahman, M., Mahmood, A., Hasan, T., Apurbo, S.: Utilization of Steel Slag in Concrete as Coarse Aggregate, 4th International Conference on Sustaintainable Construction Materials. and Technololgy, Las Vega USAs 2016, 1-11. [Online]. Available:

https://www.researchgate.net/publication/306031790_Utilization_of_Steel_Slag_in_Concrete_as_Coa rse_Aggregate

[10] Logeshwaran, M., Iswarya, P., Priyanka, P., Tamilselvam, M.: Durability Properties of Steel Slag as Coarse Aggregate in Concrete, International Research Journal of Engineering Technology, 5 (2018), 5, 621-624.

[11] Abrol, S., Verma, N., Singh, I.:Effect of Steel Slag in Concrete," International Journal Civil Engineering, 3 (2016), 2, 1-4.

[12] Subathra Devi, V., Gnanavel, B: Properties of concrete manufactured using steel slag, Procedia Engineering, 97 (2014), 95-104. Available: http://dx.doi.org/10.1016/j.proeng.2014.12.229.

[13] Saravanan, J., Suganya, N.: Mechanical Properties of Concrete Using Steel Slag Aggregate, International Journal of Engineering Inventions, 4 (2015), 9, 7-16.

[14] Palanisamy, S., Maheswaran, G., Annaamalai, M., Vennila, P.: Steel slag to improve the high strength of concrete, International Journal ChemTech Research, 7 (2015), 5, 2499-2505.

[15] Martauz, P., Vaclavik, V., Cvopa, B: The use of steel slag in concrete, IOP Conferance Series: Earth and Environment Science, 92 (2017), 1, 1-5.

[16] Liu, J., Guo, R.: Applications of Steel Slag Powder and Steel Slag Aggregate in Ultra-High Performance Concrete, Advances in Civil Engineering, 201, 1-8.

[17] Laplante, D., Aitcin, P.: Abrasion resistance of concrete, Journal of Materials in Civil Engineering, 3 (1991), 1, 19-28.

[18] Chung, D., Zeng-Qiang Shi: Improving the abrasion resistance of mortar by adding latex and carbon fibers, Cement and Concrete Research, 27 (1997), 8, 1149-1153.

[19] Bureau of Indian Standard (BIS): Specification for 53 grade Ordinary Portland Cement, IS:12269 (2004), India.

[20] Bureau of Indian Standard(BIS) : Specification for Coarse and Fine Aggregate From Natural Sources for Concrete, IS 383(2002), New Delhi,India. 
[21] Bureau of Indian Standards: Methods Of Test For Aggregates For Concrete Specific Gravity, Density, Voids, Absorption And Bulking, IS 2386 (Part III),India.

[22] Bureau of Indian Standards (BIS).: Methods of Test for Aggregates for Concrete -Part I Particle Size and Shape , IS2386 (Part I) (1997), India.[Online]. Available: http://dx.doi.org/10.4324/9780203478981.ch16

[23] Bureau of Indian Standards (BIS): Concrete Mix Proportioning - Guidelines, Indian Concrete Mix Design Guide Lines, IS 10262 (2009), India.

[24] Bureau of Indian Standards (BIS): Method of Tests for Strength of Concrete, IS 516 (2004), India.

[25] Bureau of Indian Standards (BIS) Specification for Cement Concrete Flooring Tile,IS 1237 (1997), India.

[26] ASTM (American Society for Testing and Materials): Standard Test Method for Electrical Indication of Concrete's Ability to Resist Chloride Ion Penetration,ASTM 1202 C (2012), USA.

[27] Bureau of Indian Standards (BIS): Non-Destructive Testing of Concrete - Methods of Test, IS 13311 (2004), India.

[28] Bureau of Indian Standards (BIS): Splitting Tensile Strength of Concrete - Method of Test, IS 5816 (2004), India.

[29] Bureau of Indian Standards (BIS):Method of Test for aggregate for concrete, Part II Estimation of deleterious materials and organic impurities, IS 2386 (Part II) (1963), India.

[30] Bureau of Indian Standard:Methods of Test for Aggregates for Concrete, IS 2386 ( Part IV ) (1963), India.

[31] Thomas, B., Sanjeev Kumar., Mehra P., Gupta, R. C., Joseph, M., Csetenyi L.: Abrasion resistance of sustainable green concrete containing waste tire rubber particles, Construction and Building Materials, 124 (2016), July, 906-909. 